\title{
The effect of intrauterine administration of mannose or bacteriophage on uterine health and fertility of dairy cows with special focus on Escherichia coli and Arcanobacterium pyogenes
}

\author{
V. S. Machado, M. L. S. Bicalho, R. V. Pereira, L. S. Caixeta, J. H. J. Bittar, G. Oikonomou, R. O. Gilbert, \\ and R. C. Bicalho' \\ Department of Population Medicine and Diagnostic Sciences, College of Veterinary Medicine, Cornell University, Ithaca, NY 14853
}

\begin{abstract}
The objective of this study was to evaluate the effects of intrauterine administration of $50 \mathrm{~g}$ of ultrapure mannose or a bacteriophage cocktail and the presence of Escherichia coli and Arcanobacterium pyogenes in the uterine lumen on uterine health and reproductive performance of lactating dairy cows. The study was conducted on a commercial dairy farm located near Ithaca, New York, from May 4 to January 20, 2011, and 597 cows were enrolled. The cows were divided randomly into 3 treatment groups, and treatments were administered at $2 \pm 1 \mathrm{~d}$ in milk (DIM). Treatment 1 consisted of intrauterine administration of $50 \mathrm{~g}$ of ultrapure mannose powder divided in 4 pills; treatment 2 consisted of intrauterine administration of a bacteriophage cocktail that included 4 different phages in one pill, with a dose of approximately $10^{7}$ plaqueforming units; and treatment 3 consisted of intrauterine administration of one empty pill (control). Intrauterine fluid swabs were collected on day of treatment and at $10 \pm 3$ DIM; uterine lavage samples were collected at $35 \pm 3$ DIM. Swabs and uterine lavage samples were cultured for E. coli and A. pyogenes. The intrauterine administration of mannose and bacteriophage did not affect uterine health, reproduction performance, or outcome of intrauterine secretion cultures for $E$. coli and A. pyogenes. Prevalence of intrauterine E. coli at $2 \pm 1$ DIM and $A$. pyogenes at $2 \pm 1,10 \pm 3$, and $35 \pm 3$ were affected by retained placenta. Additionally, prevalence of intrauterine E. coli at $10 \pm 3$ and A. pyogenes at 35 \pm 3 DIM were associated with metritis, and cows that were diagnosed with clinical endometritis at $35 \pm 3$ DIM had greater prevalence of intrauterine $E$. coli at 2 \pm 1 DIM and A. pyogenes at $35 \pm 3$ DIM. Furthermore, cows positive for E. coli at $2 \pm 1$ and $10 \pm 3$ DIM and for A. pyogenes at $10 \pm 3$ DIM had 1.63, 2.34, and 1.54
\end{abstract}

Received October 19, 2011.

Accepted February 13, 2012.

${ }^{1}$ Corresponding author: rcb28@cornell.edu increased odds of having metritis. Cows positive for $A$. pyogenes at $35 \pm 3 \mathrm{DIM}$ and for $E$. coli at $2 \pm 1 \mathrm{DIM}$ had 19.8 and 2.66 higher odds of being diagnosed with clinical endometritis, respectively. Additionally, cows negative for $E$. coli at $2 \pm 1$ DIM were 1.39 times more likely to conceive than cows positive cows for $E$. coli.

Key words: dairy cow, uterine cultures, bacteriophage, mannose

\section{INTRODUCTION}

Postpartum uterine diseases (specifically puerperal metritis, clinical endometritis, and subclinical endometritis) are important for animal welfare and economic reasons because they contribute to cow discomfort, elimination from the herd, and impaired reproductive performance. Puerperal metritis is defined as an abnormally enlarged uterus and a fetid, watery, red-brown uterine discharge associated with signs of systemic illness (decreased milk yield, dullness, or other signs of toxemia) and temperature $>39.5^{\circ} \mathrm{C}$ within $21 \mathrm{~d}$ after parturition, whereas endometritis is the inflammation of the uterus without systemic illness (Sheldon et al., 2006).

The uterine lumen is usually contaminated by bacteria after parturition (Foldi et al., 2006). The composition of the bacterial flora in the postpartum uterus of dairy cows differs between healthy cows and cows with metritis (Santos et al., 2011). Escherichia coli, Arcanobacterium pyogenes, and Fusobacterium necrophorum are considered important etiological agents of uterine diseases (Miller et al., 2007; Bicalho et al., 2010a; Santos et al., 2011). Moreover, the E. coli fimH gene is prevalent and expressed in E. coli that infect the postpartum uterus (Bicalho et al., 2010a; Sheldon et al., 2010). The FimH protein is an E. coli type 1 pili adhesive protein that plays an important role in the adhesion to mannosides (Krogfelt et al., 1990) and enables bacteria to colonize epithelial surfaces (Mooi and de Graaf, 1985). It is known that E. coli expressing the type 1 pili containing FimH causes urinary tract infection in humans (Kaper et al., 2004), and it is critical 
for the ability of these $E$. coli to adhere to and colonize the bladder epithelium (Mulvey, 2002). Additionally, the presence of the fim $H$ gene in intrauterine $E$. coli plays an important role in postpartum uterine diseases (Bicalho et al., 2010a). Immunization with FimH prevents $E$. coli colonization of the bladder mucosa in mice (Langermann et al., 1997), and oral treatment with FimH antagonists has the potential to reduce $E$. coli colonization in the bladder and could be an effective treatment for urinary tract infection in humans (Klein et al., 2010). Sheldon et al. (2010) reported that adhesion of intrauterine $E$. coli to endothelial cells is at least partly mediated by FimH. Therefore, mannose (a FimH antagonist) could bind to intrauterine E. coli FimH, preventing $E$. coli from adhering to the uterine mucosa (Sheldon et al., 2010) and potentially reduce the subsequent presence of $A$. pyogenes in the uterine lumen (Dohmen et al., 2000), thus reducing the occurrence of uterine diseases (Bonnett et al., 1991; Bondurant, 1999). This assumption is partly supported by the fact that King et al. (1998) reported that mannose might be effective in reducing bacterial infection in the equine endometrium.

Bacteriophages are viruses that infect bacteria; they are obligate intracellular parasites because they lack their own metabolism. Phages are host specific, able to infect only specific species or even strains of bacteria (Barrow and Soothill, 1997). Optimistic results regarding their use against certain bacterial infections have been revealed by recent randomized clinical trials in mice and cattle. Mice were successfully rescued with a single injection of a phage solution containing $3 \times$ $10^{8} \mathrm{pfu}$ of a certain bacteriophage after inoculated with lethal doses of vancomycin-resistant Enterococcus faecium (Biswas et al., 2002). Additionally, Smith and Huggins (1983) reported that bacteriophage therapy was successful when newborn, colostrum-deprived calves were inoculated with E. coli and treated with intramuscular inoculation with bacteriophages. Moreover, our research group isolated environmental bacteriophages using E. coli isolated from postpartum uterus (Bicalho et al., 2010b) and evaluated the in vitro antimicrobial activity of a bacteriophage cocktail against intrauterine E. coli (Santos et al., 2010). This cocktail was able to inhibit in vitro growth of $E$. coli isolates but its in vivo effectiveness is yet to be tested.

Ideally, treatments for uterine diseases should control pathogens from the uterus and should result in withdrawal periods for milk and meat that are as short as possible (Azawi, 2008). Systemic or intrauterine antibiotic therapy is commonly used as the treatment for metritis (Azawi, 2008). However, extensive use of antimicrobials in food animal production has contributed to the emergence of antimicrobial resistance among pathogens, which complicates the treatment of infectious diseases (Tollefson et al., 1999).

The presence of E. coli and A. pyogenes in the uterus is associated with uterine inflammation and impaired reproductive performance (Studer and Morrow, 1978; Bonnett and Martin, 1995; Bondurant, 1999). Although Studer and Morrow (1978) reported that the uterine presence of both cultures was associated with poor reproductive performance, Bonnett and Martin (1995) and Williams et al. (2005) found that only the presence of $A$. pyogenes in the uterus was associated with reproductive failure.

Therefore, the objective of this study was to evaluate the effectiveness of 2 alternative treatments (50 g of ultrapure mannose or a phage cocktail that was effective in killing intrauterine $E$. coli in vitro) for preventing metritis and reducing uterine contamination. Additionally, this study aimed to investigate the association of uterine presence of $A$. pyogenes and E. coli at 3 time points $(2 \pm 1,10 \pm 3$, and $35 \pm 3$ DIM) with uterine health and reproduction performance.

\section{MATERIALS AND METHODS}

\section{Farm and Management}

The study was conducted on a commercial dairy farm located near Ithaca, New York, from May 4, 2010, to January 20, 2011. This farm was selected because of its long working relationship with the Ambulatory and Production Medicine Clinic at Cornell University. The farm milked 2,800 Holstein cows 3 times daily in a double 52-stall parallel milking parlor. The cows were housed in freestall barns with concrete stalls covered with mattresses and bedded with manure solids. All cows were offered a TMR consisting of approximately $55 \%$ forage (corn silage, haylage, and wheat straw) and $45 \%$ concentrate (corn meal, soybean meal, canola, cottonseed, and citrus pulp) on a DM basis. The diet was formulated to meet or exceed the National Research Council nutrient requirements (NRC, 2001) for lactating Holstein cows weighing $650 \mathrm{~kg}$ and producing $45 \mathrm{~kg}$ of $3.5 \%$ FCM. Reproductive management used a combination of Presynch (Moreira et al., 2001), Ovsynch (Pursley et al., 1995), Resynch (Fricke et al., 2003), and detection of estrus, with 25 to $30 \%$ of cows bred via timed $\mathrm{AI}$ and the remainder bred after detection of estrus solely by activity monitors (Alpro, DeLaval, Kansas City, MO).

\section{Treatment Groups and Case Definition}

Before the study, statistical power and sample size calculations were performed. Considering a sample size 
of 200 cows per group, a statistical power of 0.8 , a $P$-value of 0.05 , and an overall incidence of metritis of $20 \%$, a reduction in the metritis incidence of $50 \%$ or more between treatment groups would have been statistically significant. In total, 597 cows were enrolled in the study and there were no study exclusion criteria. A total randomized field trial study design was used; cows were randomly allocated into 1 of 3 treatments groups using the random number function of Excel (Microsoft Corp., Redmond, MA). Treatment 1 consisted of intrauterine administration of $50 \mathrm{~g}$ of ultrapure mannose powder divided into 4 pills; $50 \mathrm{~g}$ of mannose is 10 times the amount used by King et al. (1998), when they effectively reduced bacterial infection in the equine endometrium. The cow's uterus is enlarged after parturition; therefore, we proposed to increase the mannose dose for this study. Treatment 2 consisted of intrauterine administration of a bacteriophage cocktail that included 4 phages in one pill with titration of approximately $10^{7} \mathrm{pfu}$. The bacteriophages used in the cocktail were isolated and tested in vitro in previous studies (Bicalho et al., 2010b; Santos et al., 2010); multiplicity of infection (MOI) as low as $10^{-4}$ affected the growth of $E$. coli when tested in vitro. Because the quantity of $E$. coli present in the postpartum uterus was unknown, the bacteriophage treatment dose was selected based on treatment production limitations. Treatment 3 consisted of the intrauterine administration of one empty pill, which was considered the control treatment. The pills used for the treatment were made from porcine gelatin (Torpac, Fairfield NJ). The treatments were administered at $2 \pm 1$ DIM by the research team as follows: cows were restrained and the perineum area was cleansed and disinfected with $70 \%$ ethanol solution. Then, a sterile swab (Har-Vet McCullough Double-Guarded Uterine Culture Swab, Spring Valley, WI) covered by a sterile pipette (inside a plastic sheath) was introduced to the cranial vagina. The pipette was manipulated through the cervix into the uterus. There, the sheath was ruptured and the swab was exposed to uterine secretion. The swab was pulled inside the pipette and kept in transportation medium at $4^{\circ} \mathrm{C}$ until it was processed in the laboratory. Subsequently, the pills were introduced with a clean sleeve to the cranial vagina and then manually through the cervix into the uterus. Swabs were cultured aerobically on MacConkey agar (Difco, Becton Dickinson, Franklin Lakes, NJ) at $37^{\circ} \mathrm{C}$, and E. coli colonies were distinguished by a purple-red color. The swabs were also cultured on Mueller-Hinton agar plates (BBL, Becton Dickinson) supplemented with 5\% defibrinated sheep blood for $48 \mathrm{~h}$ aerobically in $5 \% \mathrm{CO}_{2}$ at $38^{\circ} \mathrm{C}$. Typical A. pyogenes colonies were distinguished by colony morphology, postincubation hemolysis, and characteristic appearance on Gram stain. Metritis diagnosis was performed at $10 \pm 3$ DIM by the research team as follows: the uterus was palpated to exteriorize uterine fluids, and the presence of fetid, watery, red-brown uterine discharge was defined as metritis (Sheldon et al., 2006). Metritis peaks in the first 7 d after calving (LeBlanc, 2008); however, because of study logistics, we could only diagnose metritis at 10 \pm 3 DIM. A swab of the uterine fluids was taken and cultured as described above.

Clinical endometritis was traditionally diagnosed primarily by presence of a mucopurulent vaginal discharge (LeBlanc et al., 2002; Sheldon et al., 2006). More recently, it has been established that many cows with purulent or mucupurulent vaginal discharge are free of endometrial inflammation (Dubuc et al., 2010a,b). We therefore adapted our diagnostic procedure. Clinical endometritis was evaluated at $35 \pm 3$ DIM by visual inspection of a uterine lavage sample obtained as described by Gilbert et al. (2005). In this way, we were able to ensure that visible signs of inflammation (purulent or mucupurulent exudate) emanated from the uterus, rather than from another site. Uterine lavage sampling was performed as follows: the cow was restrained, the perineum area was cleansed and disinfected with $70 \%$ ethanol, and a plastic infusion pipette was introduced into the cranial vagina and manipulated through the cervix into the uterus. A total of $20 \mathrm{~mL}$ of sterile saline solution was infused into the uterus and agitated gently, and a sample of the fluid was aspirated. The volume of recovered fluid ranged from 5 to $15 \mathrm{~mL}$. All of the samples were visually scored by one investigator, who assessed the presence of a purulent or mucopurulent secretion in the uterine lavage sample. The score ranged from 0 to 2 , with 0 indicating absence of a purulent or mucopurulent secretion in the lavage sample, 1 indicating a bloody but not purulent sample, and 2 the presence of pus in the lavage sample. Cows with a score of 2 were considered as diagnosed with clinical endometritis. Samples were kept in ice until they were processed in the laboratory and cultured as described above.

Body condition scores were recorded at the time of each sampling using a 5-point scale with a quarterpoint system as described by Edmonson et al. (1989). Stillbirth was defined as death of a calf occurring just before, during, or within $48 \mathrm{~h}$ of parturition (Philipsson et al., 1979). Retained placenta was defined as a condition where cows fail to release their fetal membranes within $24 \mathrm{~h}$ of calving (Kelton et al., 1998), and it was diagnosed by the farm workers. Data regarding reproductive performance were extracted from the 
farm's DairyComp 305 database (Valley Agricultural Software, Tulare, CA).

\section{Statistical Analysis}

To facilitate data analysis and interpretation, the variables BCS loss (LOSS, 1 if the cow lost BCS from $1 \pm 2$ to $35 \pm 3$ DIM; 0 if cow maintained or gained BCS from $1 \pm 2$ to $35 \pm 3$ DIM), presence of clinical endometritis at $35 \pm 3($ ENDOM, yes $=1$ and no $=$ 0 ), presence of metritis $10 \pm 3$ (MET, yes $=1$ and no $=0)$, presence of retained placenta at $2 \pm 1(\mathbf{R P}$, yes $=1$ and no $=0)$, the outcome of the uterine lavage sample culture for $E$. coli at $2 \pm 1,10 \pm 3$ and $35 \pm$ 3 DIM (ECOLI1, yes $=1$ and no $=0$; ECOLI2, yes $=1$ and no $=0$; ECOLI3, yes $=1$ and no $=0$ ), and the outcome of the uterine lavage sample culture for $A$. pyogenes at $2 \pm 1,10 \pm 3$, and $35 \pm 3$ DIM (APYO1, yes $=1$ and no $=0 ; \mathbf{A P Y O 2}$, yes $=1$ and no $=0$; APYO3, yes $=1$ and no $=0$ ) were created. Additionally, descriptive statistics analysis was undertaken in SAS using the FREQ procedure (SAS Institute Inc., Cary, NC).

Two logistic regression models were fitted in SAS using the Logistic procedure to examine in detail the association of the independent variables treatment (mannose $=1$, phage $=2$, and control $=3$ ), parity, ECOLI1, ECOLI2, APYO1, APYO2, APYO3, LOSS, and RP with the odds of metritis and endometritis incidence. The association between the different uterine culture outcomes in different time points was evaluated with the use of Chi-squared analysis in JMP 9 (SAS Institute Inc., Cary, NC).

The effect of several independent variables on reproduction was analyzed by Cox's proportional hazard using the proportional hazard regression procedure in SAS. For this analysis of reproduction, cows were right-censored if not diagnosed as being pregnant before culling, death, or the end of the data collection period, which was around 210 DIM. Variables offered to the models included treatment (mannose $=1$, phage $=2$, and control $=3$ ), parity, MET, ENDOM, ECOLI1, ECOLI2, APYO1, APYO3, LOSS, and RP. To illustrate the effect of ECOLI1 on reproduction, Kaplan-Meier survival analysis was performed using MedCalc version 11.5.1.0 software (MedCalc Software, Mariakerke, Belgium); the Logrank test was used to compute $P$-values.

For all models described above, independent variables and their respective interactions were kept when $P<0.10$ in an attempt to reduce the type II error risk while maintaining a stringent type I error risk of $5 \%$. The variable treatment was forced into all statistical models, even in the absence of statistical significance.

\section{RESULTS}

The 2 treatments tested did not have any effect on the results of the outcome of intrauterine secretions cultures (Table 1), were unsuccessful in the prevention of metritis or endometritis (Table 3), and did not affect reproductive performance (Table 5). However, we forced the variable treatment into all statistical models.

The treatments did not affect the proportion of cows bred via timed AI. The percentage of cows bred via timed AI was 22.25, 25.33, and $27.83 \%$ for cows in the mannose, bacteriophage, and control groups, respectively $(P=0.14)$.

The descriptive statistics of the effect of risk factors and results regarding the outcome of the intrauterine secretion cultures are described in Table 1. Briefly, parity and BCS did not affect any of the outcomes of intrauterine secretion cultures. Retained placenta was the most important risk factor for the presence of $E$. coli and A. pyogenes in intrauterine secretions. Prevalence of intrauterine $E$. coli at $2 \pm 1$ DIM and A. pyogenes at $2 \pm 1,10 \pm 3$, and $35 \pm 3$ DIM were affected by retained placenta. Additionally, prevalence of intrauterine E. coli at $10 \pm 3$ and A. pyogenes at 35 \pm 3 DIM were associated with metritis. Moreover, cows that were diagnosed with clinical endometritis at $35 \pm$ 3 DIM had greater prevalence of intrauterine $E$. coli at $2 \pm 1 \mathrm{DIM}$ and $A$. pyogenes at $35 \pm 3$ DIM.

The association between intrauterine culture outcomes at different time points is described in Table 2 . In brief, the prevalence of $E$. coli at $10 \pm 3$ DIM and A. pyogenes at $2 \pm 1$ DIM were significantly associated with presence of $E$. coli at $2 \pm 1$ DIM. Moreover, the presence of $E$. coli at $10 \pm 3$ DIM was negatively associated with the prevalence of $A$. pyogenes at this same time point. Additionally, the presence of $A$. pyogenes at $2 \pm 1$ DIM was significantly associated with the prevalence of $A$. pyogenes at $35 \pm 3$ DIM.

Parity and presence of $E$. coli at $2 \pm 1$ and $10 \pm 3$ DIM and A. pyogenes at $10 \pm 3$ in intrauterine secretions were significantly associated with the odds of metritis (Table 3). Cows in first and second lactation had 3.8 and 1.78 higher odds of being diagnosed with metritis compared with cows in third or greater parity, respectively $(P<0.001)$. Moreover, cows positive for E. coli at $2 \pm 1$ and $10 \pm 3 \mathrm{DIM}$ and for $A$. pyogenes at $10 \pm 3$ DIM had 1.63, 2.34, and 1.54 increased odds of having metritis, respectively. Presence of E. coli at $2 \pm 1$ DIM and of $A$. pyogenes at $35 \pm 3$ DIM were significantly important for the odds of endometritis (Table 4). Cows that were positive for A. pyogenes at $35 \pm 3$ DIM had 19.8 higher odds of being diagnosed with clinical endometritis $(P<0.001)$. Additionally, cows that were $E$. coli positive at $2 \pm 1$ DIM had 
Table 1. Descriptive statistics of the effect of risk factors on the outcome of the intrauterine secretion cultures

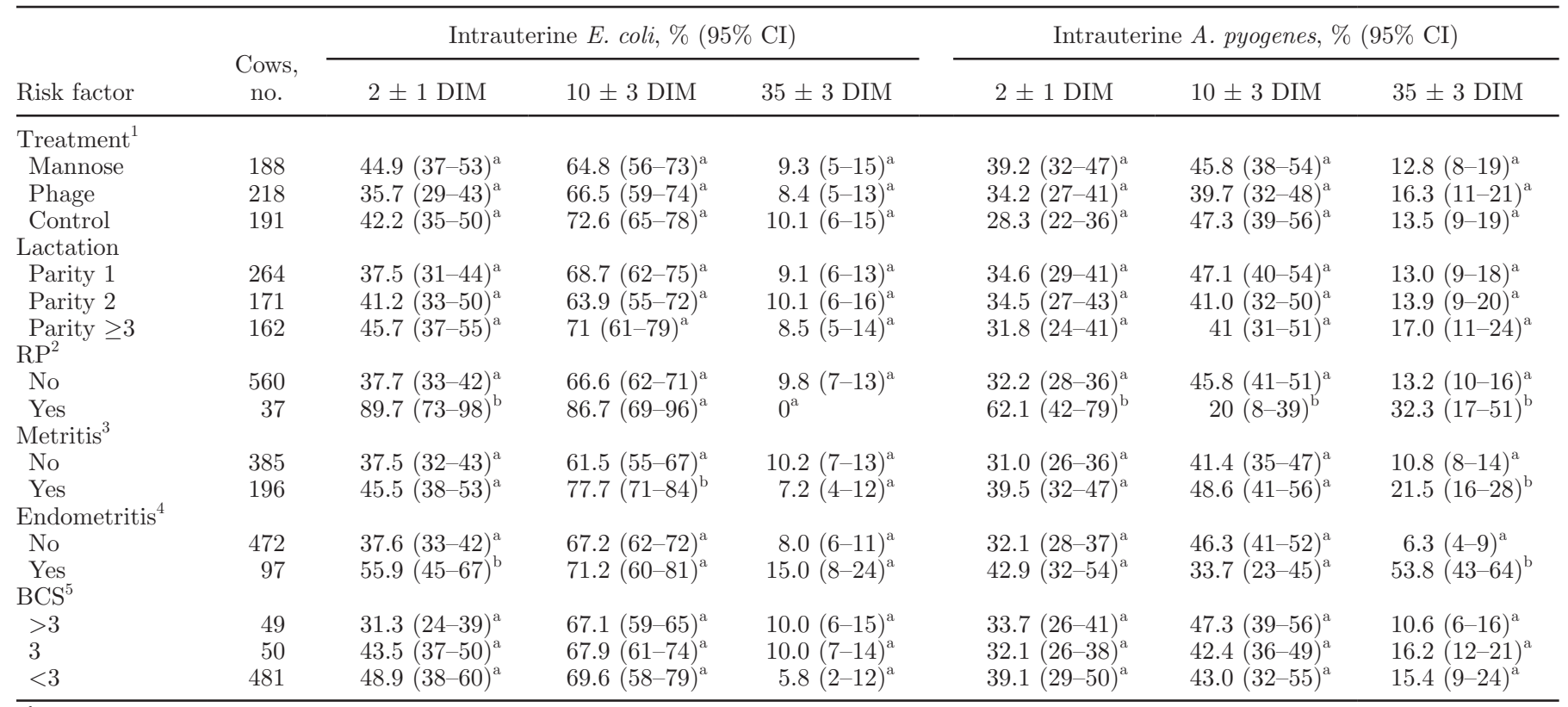

${ }^{\mathrm{a}, \mathrm{b}}$ Values with different superscripts within the same column and within a risk factor differ $(P<0.05)$.

${ }^{1}$ Mannose treatment consisted of the intrauterine administration of $50 \mathrm{~g}$ of ultrapure mannose powder divided in 4 pills; phage treatment consisted of the intrauterine administration of a bacteriophage cocktail in one pill with titration of approximately $10^{7}$ pfu; control consisted of intrauterine administration of one empty pill. Treatments were performed at $2 \pm 1$ DIM.

${ }^{2} \mathrm{RP}=$ retained placenta, where cows fail to release their fetal membranes within $24 \mathrm{~h}$ of calving.

${ }^{3}$ Metritis $=$ presence of fetid, watery, red-brown uterine discharge at $10 \pm 3$ DIM.

${ }^{4}$ Endometritis $=$ presence of pus in the uterine lavage sample performed at $35 \pm 3$ DIM.

${ }^{5} \mathrm{BCS}$ at $10 \pm 3$ DIM, using a 5-point scale with a quarter-point system as described by Edmonson et al. (1989).

Table 2. Association of intrauterine culture outcomes in different time points

\begin{tabular}{|c|c|c|c|c|c|c|c|}
\hline Culture outcome & $\begin{array}{c}\text { Cows, } \\
\text { no. }\end{array}$ & \multicolumn{3}{|c|}{ Escherichia coli positive, $\%$} & \multicolumn{3}{|c|}{ Arcanobacterium pyogenes positive, $\%$} \\
\hline \multicolumn{8}{|l|}{ E. coli culture } \\
\hline Negative & 322 & - & $63^{\mathrm{a}}$ & $9^{\mathrm{a}}$ & $31^{\mathrm{a}}$ & $45^{\mathrm{a}}$ & $13^{\mathrm{a}}$ \\
\hline Positive & 236 & - & $77^{\mathrm{b}}$ & $8^{\mathrm{a}}$ & $39^{\mathrm{b}}$ & $43^{\mathrm{a}}$ & $16^{\mathrm{a}}$ \\
\hline \multicolumn{8}{|l|}{ At $10 \pm 3$ DIM } \\
\hline \multicolumn{8}{|l|}{ At $35 \pm 3$ DIM } \\
\hline Negative & 517 & $41^{\mathrm{a}}$ & $67^{\mathrm{a}}$ & - & $33^{\mathrm{a}}$ & $45^{\mathrm{a}}$ & $14^{\mathrm{a}}$ \\
\hline Positive & 51 & $40^{\mathrm{a}}$ & $79^{\mathrm{a}}$ & - & $41^{\mathrm{a}}$ & $35^{\mathrm{a}}$ & $16^{\mathrm{a}}$ \\
\hline \multicolumn{8}{|l|}{ A. pyogenes culture } \\
\hline \multicolumn{8}{|c|}{ At $2 \pm 1$ DIM } \\
\hline Negative & 366 & $38^{\mathrm{a}}$ & $67^{\mathrm{a}}$ & $8^{\mathrm{a}}$ & - & $46^{\mathrm{a}}$ & $12^{\mathrm{a}}$ \\
\hline Positive & 192 & $46^{\mathrm{b}}$ & $71^{\mathrm{a}}$ & $11^{\mathrm{a}}$ & - & $41^{\mathrm{a}}$ & $20^{\mathrm{b}}$ \\
\hline Positive & $80^{\mathrm{a}}$ & $46^{\mathrm{b}}$ & $68^{\mathrm{a}}$ & $10^{\mathrm{a}}$ & $46^{\mathrm{b}}$ & $36^{\mathrm{a}}$ & - \\
\hline
\end{tabular}

${ }^{\mathrm{a}, \mathrm{b}}$ Values with different superscripts within the same column differ $(P<0.05)$. 
Table 3. Effects of treatment, lactation number, and the outcome of the intrauterine secretion cultures (for Escherichia coli and Arcanobacterium pyogenes) on the odds of metritis incidence estimated with the use of logistic regression models

\begin{tabular}{lcccc}
\hline Variable & $\begin{array}{c}\text { Cows, } \\
\text { no. }\end{array}$ & $\begin{array}{c}\text { Metritis }^{2} \\
\text { incidence, } \%\end{array}$ & $\begin{array}{c}\text { Adjusted } \\
\text { odds ratio }\end{array}$ & $P$-value \\
\hline Mannose $^{1}$ & 188 & 35.5 & 0.87 & 0.86 \\
Phage & 218 & 30.5 & 0.93 & \\
Control & 191 & 35.0 & Baseline & \\
Parity 1 & 264 & 47.8 & 3.80 & $<0.001$ \\
Parity 2 & 171 & 25.0 & 1.78 & \\
Parity $\geq 3$ & 162 & 17.4 & Baseline & \\
E. coli negative $(2 \pm 1$ DIM) & 322 & 30.0 & Baseline & 0.02 \\
E. coli positive $(2 \pm 1$ DIM) & 236 & 37.4 & 1.63 & $<0.001$ \\
E. coli negative $(10 \pm 3$ DIM) & 149 & 27.1 & Baseline & \\
E. coli positive $(10 \pm 3$ DIM) & 330 & 44.7 & 2.34 & 0.05 \\
A. pyogenes negative $(10 \pm 3$ DIM) & 270 & 36.0 & Baseline & \\
A. pyogenes positive $(10 \pm 3$ DIM) & 209 & 42.9 & 1.54 & \\
\hline
\end{tabular}

${ }^{1}$ Mannose treatment consisted of the intrauterine administration of $50 \mathrm{~g}$ of ultrapure mannose powder divided in 4 pills; phage treatment consisted of the intrauterine administration of a bacteriophage cocktail in one pill with titration of approximately $10^{7} \mathrm{pfu}$; control consisted of intrauterine administration of one empty pill. Treatments were performed at $2 \pm 1$ DIM.

${ }^{2}$ Metritis $=$ presence of fetid, watery, red-brown uterine discharge at $10 \pm 3$ DIM.

2.66 higher odds of having clinical endometritis $(P=$ $0.002)$.

A multivariable Cox proportional hazard model was performed to evaluate the effect of several variables on reproduction (Table 5). The only variables retained in this model were treatment, parity, and the presence of $E$. coli in intrauterine secretions at $2 \pm 1$ DIM. Treatment had no effect on reproduction. Conversely, cows in parity 1 and 2 were 1.6 and 1.5 more likely to conceive than cows in parity $\geq 3$, respectively $(P=0.02)$. Cows that were negative for $E$. coli at $2 \pm 1$ DIM were 1.39 times more likely to conceive than cows positive for $E$. coli. By 200 DIM, $80 \%$ of cows those negative for $E$. coli at $2 \pm 1$ DIM were pregnant, and only $68 \%$ of positive cows had conceived (Figure 1).

\section{DISCUSSION}

We were encouraged by results of previous studies to perform this clinical trial with the aim of establishing alternatives for prophylaxis and treatment for postpartum uterine diseases. Given the growing interest in reducing the use of antibiotics in farm animals, any positive results from this study could be considered important.

Bacteriophages could be beneficial for metritis treatment because decreasing the bacterial load of $E$. coli is likely to decrease the severity of the disease (Sheldon et al., 2006). Bacteriophages have been successfully used in animal trials against a broad range of pathogenic E. coli (Brüssow, 2005). Previous stud-

Table 4. Effects of treatment, lactation number, and the outcome of the intrauterine secretion cultures (for Escherichia coli and Arcanobacterium pyogenes) on the odds of endometritis incidence estimated with the use of logistic regression models

\begin{tabular}{|c|c|c|c|c|}
\hline Variable & $\begin{array}{c}\text { Cows, } \\
\text { no. }\end{array}$ & $\begin{array}{c}\text { Endometritis }{ }^{1} \\
\text { incidence, } \%\end{array}$ & $\begin{array}{l}\text { Adjusted } \\
\text { odds ratio }\end{array}$ & $P$-value \\
\hline Mannose $^{2}$ & 188 & 15.1 & 0.65 & 0.55 \\
\hline Phage & 218 & 17.7 & 0.93 & \\
\hline Control & 191 & 17.3 & Baseline & \\
\hline Parity 1 & 264 & 19.0 & 1.22 & 0.09 \\
\hline Parity 2 & 171 & 11.3 & 0.50 & \\
\hline Parity $\geq 3$ & 162 & 19.0 & Baseline & \\
\hline E. coli negative ( $2 \pm 1$ DIM $)$ & 322 & 12.0 & Baseline & 0.002 \\
\hline E. coli positive ( $2 \pm 1$ DIM $)$ & 236 & 22.4 & 2.66 & \\
\hline A. pyogenes negative $(35 \pm 3 \mathrm{DIM})$ & 487 & 9.1 & Baseline & $<0.001$ \\
\hline A. pyogenes positive ( $35 \pm 3 \mathrm{DIM})$ & 80 & 63.3 & 19.8 & \\
\hline
\end{tabular}


Table 5. Cox's proportional hazard analysis evaluating the effect of treatment ${ }^{1}$ (mannose, phage, and control) on the hazard of pregnancy; the variables parity and first Escherichia coli culture (DIM $=2 \pm 1$ ) were also retained in the model

\begin{tabular}{lccc}
\hline Variable & $\begin{array}{c}\text { Cows, } \\
\text { no. }\end{array}$ & $\begin{array}{c}\text { Adjusted } \\
\text { hazard ratio }\end{array}$ & $P$-value \\
\hline Mannose & 188 & 0.92 & 0.89 \\
Phage & 218 & 0.65 & \\
Control & 191 & Baseline & 0.02 \\
Parity 1 & 264 & 1.6 & \\
Parity 2 & 171 & 1.5 & 0.008 \\
Parity $\geq 3$ & 162 & Baseline & \\
E. coli negative $(2 \pm 1 \mathrm{DIM})$ & 322 & Baseline & 0.72 \\
E. coli positive $(2 \pm 1 \mathrm{DIM})$ & 236 & & \\
\hline
\end{tabular}

${ }^{1}$ Mannose treatment consisted of the intrauterine administration of $50 \mathrm{~g}$ of ultrapure mannose powder divided in 4 pills; phage treatment consisted of the intrauterine administration of a bacteriophage cocktail in one pill with titration of approximately $10^{7} \mathrm{pfu}$; control consisted of intrauterine administration of one empty pill.

Treatments were performed at $2 \pm 1$ DIM.

ies isolated environmental bacteriophages using $E$. coli isolated from postpartum uterus, estimated their lytic activity (Bicalho et al., 2010b), and evaluated the in vitro antimicrobial activity of a bacteriophage cocktail against intrauterine E. coli (Santos et al., 2010). This cocktail had a notable capacity to inhibit the in vitro growth of E. coli isolates. Unfortunately, in the current study, bacteriophage therapy did not have any effect on metritis incidence. A possible explanation could be that bacteriophages are host specific, able to infect only specific species or even strains of bacteria (Barrow and Soothill, 1997). In vitro, MOI $=10^{1}$ and $\mathrm{MOI}>10^{2}$ were efficient in inhibiting 50 and $90 \%$ of all isolates tested, respectively (Santos et al., 2010). Even though the bacteriophage cocktail showed good effectiveness in killing intrauterine $E$. coli in vitro, the genetic vari-

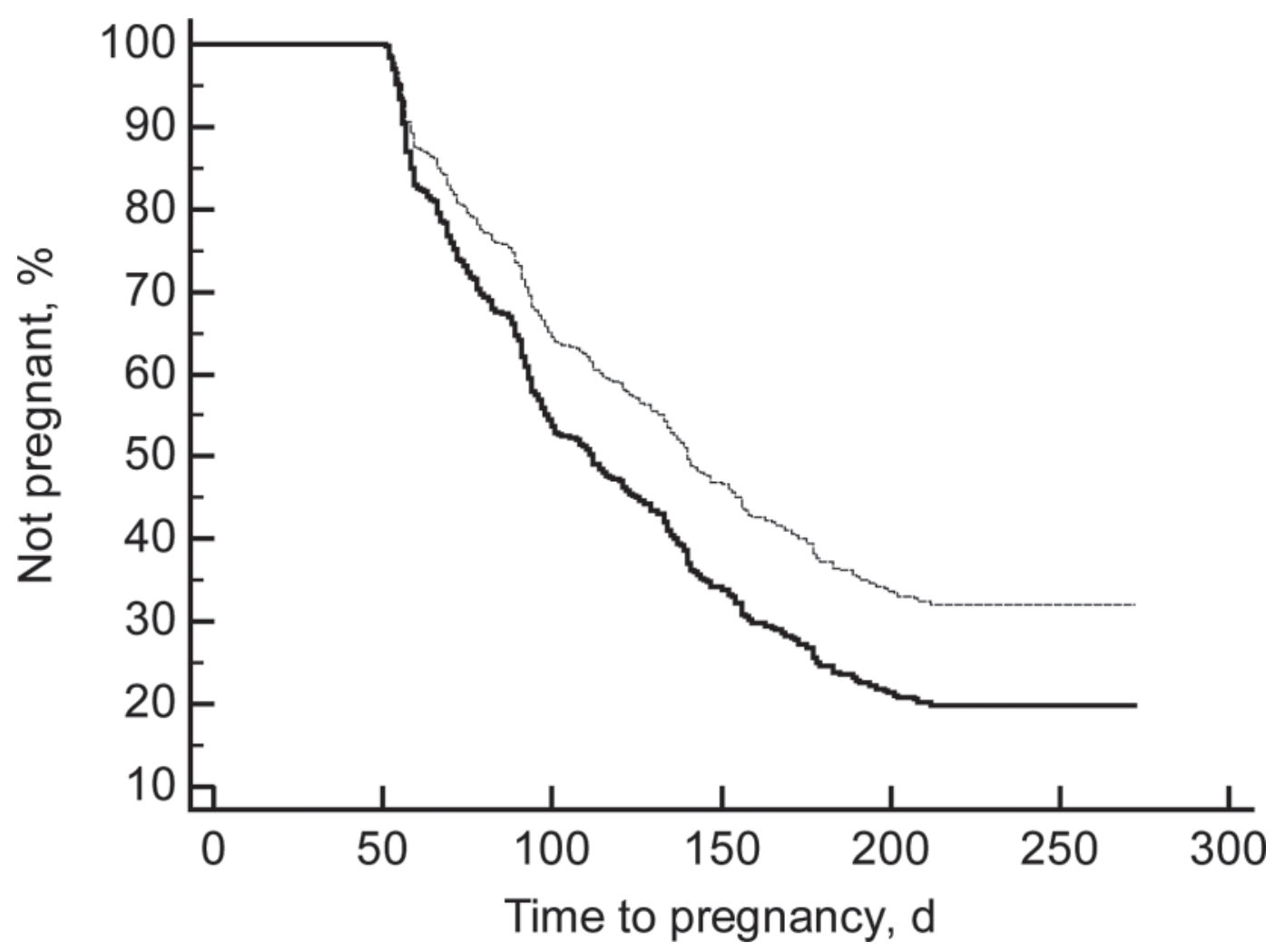

Figure 1. Kaplan-Meier survival analysis of calving-to-conception interval by the outcome of intrauterine secretion culture of Escherichia coli $(\mathrm{DIM}=2 \pm 1)$. Cows that were positive for intrauterine $E$. coli culture at $2 \pm 1$ DIM (dotted line) had a median calving-to-conception interval of $142 \mathrm{~d}$ compared with $101 \mathrm{~d}$ for cows that were negative for E. coli (solid line). 
ability of intrauterine E. coli strains is large (Bicalho et al., 2010a), and the quantity of E. coli present in the postpartum uterus was unknown. This might have affected the spectrum of activity of the bacteriophages used and could have decreased the effectiveness of the cocktail in vivo. Additionally, the activity of the phages when in the intrauterine environment is unknown, and the lochia secretion present in early postpartum uterus might have inhibited bacteriophage activity. However, a previous study showed that in a model system that simulated intestinal conditions, an Enterobacter aerogenes-specific bacteriophage persisted for a prolonged period and proliferated in reactors simulating the different parts of the large intestine (Verthé et al., 2004). Furthermore, Waseh et al. (2010) reported that salmonella colonization in chickens was reduced by orally administered bacteriophage. These studies show that bacteriophages can survive and maintain their activity under in vivo conditions; however, further research is needed in this area.

The inclusion of the mannose treatment was also encouraged by previous studies. Bicalho et al. (2010a) found that FimH, an E. coli type 1 pili adhesive protein that plays an important role in adhesion to mannosides and enables the bacteria to colonize epithelial surfaces (Mooi and de Graaf, 1985), is very important for metritis and endometritis. In addition, King et al. (1998) reported that mares receiving a $100-\mathrm{mL}$ intrauterine infusion of $E$. coli $\left(10^{9}\right.$ cells suspended in sterile PBS) alone accumulated more intrauterine fluid at $24 \mathrm{~h}$ than mares that received $100 \mathrm{~mL}$ of E. coli $\left(10^{9}\right.$ cells $)$ suspended in PBS containing $50 \mathrm{mg}$ of mannose $/ \mathrm{mL}$, whereas prevalence of positive culture at $24 \mathrm{~h}$ was significantly reduced in the mannose-treated group. Ultrapure mannose was used because it would be applied as an intrauterine treatment; hence, it would be in direct contact with intrauterine E. coli. Mannose treatment in vitro was efficient in decreasing the ability of intrauterine E. coli to adhere to endometrial cells (Sheldon et al., 2010). One strong explanation for the ineffectiveness of this treatment in the current study is that the mannose concentration was unlikely to be at the same level $(2.5 \%)$ as used in the in vitro test (Sheldon et al., 2010). In early postpartum, the uterus is enlarged and the uterine volume is probably greater than $2 \mathrm{~L}$, which was the exact uterine volume needed to have an intrauterine mannose concentration of $2.5 \%$. However, the quantity of mannose used in this study was 10 times more than was used in a previous trial (King et al., 1998). Other possibilities could decrease the mannose concentration in the uterus; for example, part of the treatment could have been carried out of the uterus by lochia; osmotic pressure could have been caused by the introduction of the treatment in the uterine lumen, and this might have caused a decrease in mannose concentration in the uterus; or the mannose could have been used as a carbon source by bacteria (Kornberg and Lambourne, 1992). Additionally, the uterine environment might influence the binding mechanism between mannose and FimH.

In total, 597 cows were enrolled on this trial; the observed metritis incidence was 35.5, 30.5, and 35\% and that of endometritis was 15.1, 17.7, and $17.3 \%$ for the mannose, phage, and control groups, respectively. Therefore, given our sample size and the observed differences in uterine disease incidence, we estimated that our study had a statistical power of 0.7 to 0.8 to demonstrate that the evaluated treatments had no effect on the incidence of metritis and endometritis.

Although the treatments tested were not effective for prevention of uterine diseases, interesting findings regarding uterine bacteriology in 3 periods are shown in this study. Retained placenta was the most important risk factor for uterine contamination, principally in the first 3 DIM. Before calving, the uterus is sterile, whereas after parturition, bacteria may enter the uterine lumen ascending from the environment (Foldi et al., 2006); retained placenta is an important risk factor for uterine bacterial contamination (Paisley et al., 1986) and is also known to be an important risk factor for metritis (Bruun et al., 2002). Additionally, in the present study, first- and second-lactation cows were more likely to be diagnosed with metritis. This can be explained by the fact that the incidence of dystocia is higher in cows in first and second lactation (Bonneville-Hébert et al., 2011), and dystocia is one of the risk factors of metritis (Bruun et al., 2002; Benzaquen et al., 2007; Ghavi Hossein-Zadeh and Ardalan, 2011). However, first- and second-parity cows had better reproductive performance, and this result is supported by previous studies (Benzaquen et al., 2007; Machado et al., 2010).

Presence of $E$. coli at $2 \pm 1$ DIM had the most detrimental effect on uterine health and reproductive performance. Presence of E. coli at $2 \pm 1$ and $10 \pm$ 3 DIM and of $A$. pyogenes at $10 \pm 3$ DIM were significantly important for the odds of metritis incidence. These results are supported by previous studies that found that $E$. coli and A. pyogenes were two of the most prevalent bacterial species associated with uterine diseases and reproductive failure (Studer and Morrow, 1978; Bonnett et al., 1991; Bondurant, 1999). Additionally, a study performed in buffalos reported that $E$. coli and $A$. pyogenes were mainly present in uteri affected by metritis (Azawi et al., 2007). Moreover, presence of $E$. coli at $2 \pm 1 \mathrm{DIM}$ and $A$. pyogenes at 35 \pm 3 DIM were important for the odds of endometritis incidence; however, only the presence of $E$. coli at $2 \pm$ 1 DIM impaired reproductive performance. It has been 
reported that uterine $E$. coli are merely opportunistic environmental bacteria, because none of the virulence factors evaluated were associated with the probability of occurrence of uterine diseases (Silva et al., 2009). On the other hand, Bicalho et al. (2010a) reported that $E$. coli virulence factors, such as fimH, hlyA, cdt, kpsMII, $i b e A$, and ast $A$, were associated with uterine diseases and impaired reproductive performance, and these 5 virulence factors were not evaluated in the Silva et al. (2009) study. Additionally, Dohmen et al. (2000) reported that the presence of $E$. coli and intrauterine endotoxin in the first 2 DIM were positively associated with the presence of $A$. pyogenes plus gram-negative bacteria at 14 DIM, supporting the hypothesis that an early postpartum uterine $E$. coli infection would affect uterine health. However, this same association was not observed in this study; the presence of $E$. coli at $2 \pm 1$ DIM was not directly associated with the presence of A. pyogenes at $10 \pm 3$ DIM. Presence of E. coli at $2 \pm$ 1 DIM was associated with subsequent presence of $E$. coli at $10 \pm 3$ DIM, which was also associated with the incidence of metritis. This supports our findings that the presence of $E$. coli at $2 \pm 1$ DIM was important for uterine health parameters and impaired reproduction performance. However, Williams et al. (2005) did not find any association between $E$. coli and reproduction failure, and reported that the only species associated with impaired reproduction performance was $A$. pyogenes. Furthermore, Bonnett and Martin (1995) found that the presence of $A$. pyogenes at 26 DIM was associated with poor reproductive performance.

\section{CONCLUSIONS}

In conclusion, intrauterine administrations of $50 \mathrm{~g}$ of mannose or bacteriophage cocktail at $2 \pm 1$ DIM were not effective in improving uterine health in dairy cows. Additionally, we found that parity and presence of $E$. coli at $2 \pm 1$ and $10 \pm 3 \mathrm{DIM}$ and that of $A$. pyogenes at $10 \pm 3$ DIM in intrauterine secretions were significantly associated with the odds of metritis. Furthermore, presence of $E$. coli at $2 \pm 1 \mathrm{DIM}$ and $A$. pyogenes at 35 \pm 3 DIM were significantly important for the odds of endometritis. Additionally, cows negative for E. coli at $2 \pm 1$ DIM were more likely to conceive than cows positive for $E$. coli at this time point.

\section{REFERENCES}

Azawi, O. I. 2008. Postpartum uterine infection in cattle. Anim. Reprod. Sci. 105:187-208.

Azawi, O. I., S. N. Omran, and J. J. Hadad. 2007. Clinical, bacteriological, and histopathological study of toxic puerperal metritis in Iraqi buffalo. J. Dairy Sci. 90:4654-4660.
Barrow, P. A., and J. S. Soothill. 1997. Bacteriophage therapy and prophylaxis: Rediscovery and renewed assessment of potential. Trends Microbiol. 5:268-271.

Benzaquen, M. E., C. A. Risco, L. F. Archbald, P. Melendez, M. J. Thatcher, and W. W. Thatcher. 2007. Rectal temperature, calving-related factors, and the incidence of puerperal metritis in postpartum dairy cows. J. Dairy Sci. 90:2804-2814.

Bicalho, R. C., V. S. Machado, M. L. Bicalho, R. O. Gilbert, A. G. Teixeira, L. S. Caixeta, and R. V. Pereira. 2010a. Molecular and epidemiological characterization of bovine intrauterine Escherichia coli. J. Dairy Sci. 93:5818-5830.

Bicalho, R. C., T. M. Santos, R. O. Gilbert, L. S. Caixeta, L. M. Teixeira, M. L. Bicalho, and V. S. Machado. 2010b. Susceptibility of Escherichia coli isolated from uteri of postpartum dairy cows to antibiotic and environmental bacteriophages. Part I: Isolation and lytic activity estimation of bacteriophages. J. Dairy Sci. 93:93104.

Biswas, B., S. Adhya, P. Washart, B. Paul, A. N. Trostel, B. Powell, R. Carlton, and C. R. Merril. 2002. Bacteriophage therapy rescues mice bacteremic from a clinical isolate of vancomycin-resistant $E n-$ terococcus faecium. Infect. Immun. 70:204-210.

Bondurant, R. H. 1999. Inflammation in the bovine female reproductive tract. J. Anim. Sci. 77(Suppl. 2):101-110.

Bonnett, B. N., and S. W. Martin. 1995. Path analysis of peripartum and postpartum events, rectal palpation findings, endometrial biopsy results and reproductive performance in Holstein-Friesian dairy cows. Prev. Vet. Med. 21:279-288.

Bonnett, B. N., S. W. Martin, V. P. Gannon, R. B. Miller, and W. G. Etherington. 1991. Endometrial biopsy in Holstein-Friesian dairy cows. III. Bacteriological analysis and correlations with histological findings. Can. J. Vet. Res. 55:168-173.

Bonneville-Hébert, A., E. Bouchard, D. D. Tremblay, and R. Lefebvre. 2011. Effect of reproductive disorders and parity on repeat breeder status and culling of dairy cows in Quebec. Can. J. Vet. Res. 75:147-151.

Brüssow, H. 2005. Phage therapy: The Escherichia coli experience. Microbiology 151:2133-2140.

Bruun, J., A. K. Ersboll, and L. Alban. 2002. Risk factors for metritis in Danish dairy cows. Prev. Vet. Med. 54:179-190.

Dohmen, M. J., K. Joop, A. Sturk, P. E. Bols, and J. A. Lohuis 2000. Relationship between intra-uterine bacterial contamination, endotoxin levels and the development of endometritis in postpartum cows with dystocia or retained placenta. Theriogenology 54:1019-1032

Dubuc, J., T. F. Duffield, K. E. Leslie, J. S. Walton, and S. J. LeBlanc. 2010a. Definitions and diagnosis of postpartum endometritis in dairy cows. J. Dairy Sci. 93:5225-5233.

Dubuc, J., T. F. Duffield, K. E. Leslie, J. S. Walton, and S. J. LeBlanc. 2010b. Risk factors for postpartum uterine diseases in dairy cows. J. Dairy Sci. 93:5764-5771.

Edmonson, A. J., I. J. Lean, L. D. Weaver, T. Farver, and G. Webster. 1989. A body condition scoring chart for Holstein dairy cows. J. Dairy Sci. 72:68-78.

Földi, J., M. Kulcsar, A. Pecsi, B. Huyghe, C. de Sa, J. A. Lohuis, P. Cox, and G. Huszenicza. 2006. Bacterial complications of postpartum uterine involution in cattle. Anim. Reprod. Sci. 96:265-281.

Fricke, P. M., D. Z. Caraviello, K. A. Weigel, and M. L. Welle. 2003 Fertility of dairy cows after resynchronization of ovulation at three intervals following first timed insemination. J. Dairy Sci. 86:3941-3950.

Ghavi Hossein-Zadeh, N., and M. Ardalan. 2011. Cow-specific risk factors for retained placenta, metritis and clinical mastitis in Holstein cows. Vet. Res. Commun. 35:345-354.

Gilbert, R. O., S. T. Shin, C. L. Guard, H. N. Erb, and M. Frajblat. 2005. Prevalence of endometritis and its effects on reproductive performance of dairy cows. Theriogenology 64:1879-1888.

Kaper, J. B., J. P. Nataro, and H. L. Mobley. 2004. Pathogenic Escherichia coli. Nat. Rev. Microbiol. 2:123-140.

Kelton, D. F., K. D. Lissemore, and R. E. Martin. 1998. Recommendations for recording and calculating the incidence of selected clinical diseases of dairy cattle. J. Dairy Sci. 81:2502-2509. 
King, S. S., E. M. Carnevale, L. G. Nequin, and J. J. Crawford. 1998. Inhibition of bacterial endometritis with mannose. J. Equine Vet. Sci. 18:332-334.

Klein, T., D. Abgottspon, M. Wittwer, S. Rabbani, J. Herold, X. Jiang, S. Kleeb, C. Luthi, M. Scharenberg, J. Bezencon, E. Gubler, L. Pang, M. Smiesko, B. Cutting, O. Schwardt, and B. Ernst. 2010. FimH antagonists for the oral treatment of urinary tract infections: From design and synthesis to in vitro and in vivo evaluation. J. Med. Chem. 53:8627-8641.

Kornberg, H. L., and L. T. Lambourne. 1992. Role of the phosphoenolpyruvate-dependent fructose phosphotransferase system in the utilization of mannose by Escherichia coli. Proc. Biol. Sci. 250:51-55.

Krogfelt, K. A., H. Bergmans, and P. Klemm. 1990. Direct evidence that the FimH protein is the mannose-specific adhesin of Escherichia coli type 1 fimbriae. Infect. Immun. 58:1995-1998.

Langermann, S., S. Palaszynski, M. Barnhart, G. Auguste, J. S. Pinkner, J. Burlein, P. Barren, S. Koenig, S. Leath, C. H. Jones, and S. J. Hultgren. 1997. Prevention of mucosal Escherichia coli infection by FimH-adhesin-based systemic vaccination. Science 276:607-611.

LeBlanc, S. J. 2008. Postpartum uterine disease and dairy herd reproductive performance: A review. Vet. J. 176:102-114.

LeBlanc, S. J., T. F. Duffield, K. E. Leslie, K. G. Bateman, G. P. Keefe, J. S. Walton, and W. H. Johnson. 2002. Defining and diagnosing postpartum clinical endometritis and its impact on reproductive performance in dairy cows. J. Dairy Sci. 85:2223-2236.

Machado, V. S., L. S. Caixeta, J. A. McArt, and R. C. Bicalho. 2010. The effect of claw horn disruption lesions and body condition score at dry-off on survivability, reproductive performance, and milk production in the subsequent lactation. J. Dairy Sci. 93:40714078.

Miller, A. N., E. J. Williams, K. Sibley, S. Herath, E. A. Lane, J. Fishwick, D. M. Nash, A. N. Rycroft, H. Dobson, C. E. Bryant, and I. M. Sheldon. 2007. The effects of Arcanobacterium pyogenes on endometrial function in vitro, and on uterine and ovarian function in vivo. Theriogenology 68:972-980.

Mooi, F. R., and F. K. de Graaf. 1985. Molecular biology of fimbriae of enterotoxigenic Escherichia coli. Curr. Top. Microbiol. Immunol. 118:119-138.

Moreira, F., C. Orlandi, C. A. Risco, R. Mattos, F. Lopes, and W. W. Thatcher. 2001. Effects of presynchronization and bovine somatotropin on pregnancy rates to a timed artificial insemination protocol in lactating dairy cows. J. Dairy Sci. 84:1646-1659.

Mulvey, M. A. 2002. Adhesion and entry of uropathogenic Escherichia coli. Cell. Microbiol. 4:257-271.

NRC. 2001. Nutrient Requirements of Dairy Cattle. 7th ed. Natl. Acad. Press, Washington, DC.

Paisley, L. G., W. D. Mickelsen, and P. B. Anderson. 1986. Mechanisms and therapy for retained fetal membranes and uterine infections of cows: A review. Theriogenology 25:353-381.
Philipsson, J., J. L. Foulley, J. Lederer, T. Liboriussen, and A. Osinga. 1979. Sire evaluation standards and breeding strategies for limiting dystocia and stillbirth. Report of an E.E.C./E.A.A.P. working group. Livest. Prod. Sci. 6:111-127.

Pursley, J. R., M. O. Mee, and M. C. Wiltbank. 1995. Synchronization of ovulation in dairy cows using $\mathrm{PGF}_{2 \alpha}$ and GnRH. Theriogenology 44:915-923.

Santos, T. M., R. O. Gilbert, and R. C. Bicalho. 2011. Metagenomic analysis of the uterine bacterial microbiota in healthy and metritic postpartum dairy cows. J. Dairy Sci. 94:291-302.

Santos, T. M., R. O. Gilbert, L. S. Caixeta, V. S. Machado, L. M. Teixeira, and R. C. Bicalho. 2010. Susceptibility of Escherichia coli isolated from uteri of postpartum dairy cows to antibiotic and environmental bacteriophages. Part II: In vitro antimicrobial activity evaluation of a bacteriophage cocktail and several antibiotics. J. Dairy Sci. 93:105-114.

Sheldon, I. M., G. S. Lewis, S. LeBlanc, and R. O. Gilbert. 2006. Defining postpartum uterine disease in cattle. Theriogenology 65:1516-1530.

Sheldon, I. M., A. N. Rycroft, B. Dogan, M. Craven, J. J. Bromfield, A. Chandler, M. H. Roberts, S. B. Price, R. O. Gilbert, and K. W. Simpson. 2010. Specific strains of Escherichia coli are pathogenic for the endometrium of cattle and cause pelvic inflammatory disease in cattle and mice. PLoS ONE 5:e9192.

Silva, E., S. Leitao, T. Tenreiro, C. Pomba, T. Nunes, L. Lopes da Costa, and L. Mateus. 2009. Genomic and phenotypic characterization of Escherichia coli isolates recovered from the uterus of puerperal dairy cows. J. Dairy Sci. 92:6000-6010.

Smith, H. W., and M. B. Huggins. 1983. Effectiveness of phages in treating experimental Escherichia coli diarrhoea in calves, piglets and lambs. J. Gen. Microbiol. 129:2659-2675.

Studer, E., and D. A. Morrow. 1978. Postpartum evaluation of bovine reproductive potential: Comparison of findings from genital tract examination per rectum, uterine culture, and endometrial biopsy. J. Am. Vet. Med. Assoc. 172:489-494.

Tollefson, L., P. J. Fedorka-Cray, and F. J. Angulo. 1999. Public health aspects of antibiotic resistance monitoring in the USA. Acta Vet. Scand. Suppl. 92:67-75.

Verthé, K., S. Possemiers, N. Boon, M. Vaneechoutte, and W. Verstraete. 2004. Stability and activity of an Enterobacter aerogenesspecific bacteriophage under simulated gastro-intestinal conditions. Appl. Microbiol. Biotechnol. 65:465-472.

Waseh, S., P. Hanifi-Moghaddam, R. Coleman, M. Masotti, S. Ryan, M. Foss, R. MacKenzie, M. Henry, C. M. Szymanski, and J. Tanha. 2010. Orally administered P22 phage tailspike protein reduces salmonella colonization in chickens: Prospects of a novel therapy against bacterial infections. PLoS ONE 5:e13904.

Williams, E. J., D. P. Fischer, D. U. Pfeiffer, G. C. England, D. E. Noakes, H. Dobson, and I. M. Sheldon. 2005. Clinical evaluation of postpartum vaginal mucus reflects uterine bacterial infection and the immune response in cattle. Theriogenology 63:102-117. 